\title{
Simulation of WAG and Gas Injection with Potential Sweep Improvement by Application of Foam
}

\author{
* Surguchev L. M., ** Coombe D. A., * Hanssen J. E., *** Svorstoel L. \\ * RF - Rogaland Research, Norway \\ ** Computer Mod. Group, Canada \\ *** Saga Petroleum a. s., Norway
}

\begin{abstract}
Copyright 1995, Steering Committee of the European IOR - Symposium.
This paper was presented at the 8th. European IOR - Symposium in Vienna, Austria, May 15 - 17, 1995

This paper was selected for presentation by the Steering Committee, following review of information contained in an abstract submitted by the author(s). The paper, as presented has not been reviewed by the Steering Committee.
\end{abstract}

\section{ABSTRACT}

Stratified oil reservoirs with high permeability contrast and moderate structural dip are considered today as potential candidates for WAG and/or for downdip gas injection. The combination of waterflooding and gas injection processes in WAG as well as updip gas injection are well known processes, quite intensively studied for North Sea application. This simulation study aims to compare different gas-assisted processes and has a focus on the importance of anisotropy and vertical inter-layer communication in stratified reservoirs for these methods.

Three different foam processes were modelled with a fully-featured, field scale reservoir simulator having flexible foam modelling capabilities: (i) in-depth mobility control by foam injection, (ii) injectant diversion by in situ generation of foam from a foaming agent slug injected as part of a WAG process, and (iii) foam treatment of a production well against gas coning and cusping. The sensitivity of the base cases as well as the foam processes to critical reservoir and foam parameters are evaluated in the simulations, using typical laboratory data as the starting input and studying realistic ranges of variation.

This study illustrates that a foam reservoir simulator is a useful and important tool in the on-going screening of potential reservoir applications of foam. The data in the paper will allow making first-order recommendations on process selection depending on the stratification characteristics of the reservoir. The potential of foam to improve sweep efficiency of gas and WAG methods is evaluated and relative merit of foam processes compared in various circumstances of relevance for obtaining an optimal management of complex reservoirs in the North Sea and elsewhere.

\section{INTRODUCTION}

Improved oil recovery (IOR) methods based on gas injection have significant potential for stratified heterogeneous reservoirs of complex geology ${ }^{1}$. Gas injection may enhance oil displacement and recovery in reservoirs where traditional waterflooding might have limited efficiency and applicability ${ }^{2}$. The sweep efficiency of continuous gas injection can be improved by combination with waterflooding in Water-AlternateGas (WAG) injection mode ${ }^{3}$. Application of foam may provide further assistance in improving the sweep efficiency of gas and WAG injection 4,5 .

Several gas and WAG injection field projects are under implementation today in the North Sea fields. Updip, gravity-stabilised gas injection and downdip WAG injection are the most widely applied technologies in stratified reservoirs 6 . Foam processes are being considered for North Sea oil reservoirs to improve the efficiency of gas injection methods further. Foam is a priority topic in the ongoing Norwegian IOR research program RUTH ${ }^{7,8}$.

The high mobility and low density of gas in a reservoir may cause a number of flow problems leading to the low sweep. A foam confined inside the pore network has many properties that are desirable for controlling gas flow. The dispersed microstructure, with pore-bridging liquid films separating individual gas bubbles, gives foam its unique ability to selectively reduce gas mobility ${ }^{9}$. Foam has been used or considered for increasing the sweep efficiency of injected gas (vertical and lateral), for blocking and diverting injected gas from entering high-permeable zones or fractures, and for treating production wells suffering from unacceptably high gas/ oil ratio (GOR) levels 8 . 


\section{IDEALISED RESERVOIR MODEL}

In the North Sea, the main targets for gas based IOR methods are the stratified sandstone reservoirs 7,8 . A generic reservoir model was defined in order to capture the key features of a typical sandstone formation considered most critical for foam application. This model represents a dipping reservoir $\left(8^{\circ}\right)$ as a layered cross-section having one injector and one producer. Grid blocks near the wells have a gradually finer symmetrical resolution. The reservoir has a highpermeable $(2000 \mathrm{mD})$ layer above a lower-permeable $(200 \mathrm{mD})$ layer. The properties of the generic reservoir model are listed in Table 1.

Table 1: Properties of the idealised North Sea reservoir.

\begin{tabular}{|l|c|c|c|}
\hline & $\begin{array}{c}\text { Upper } \\
\text { layer }\end{array}$ & $\begin{array}{c}\text { Lower } \\
\text { layer }\end{array}$ & Total \\
\hline Length, $m$ & 1000 & 1000 & 1000 \\
Width. $m$ & 200 & 200 & 200 \\
Thickness, $m$ & 30 & 30 & 60 \\
\hline $\begin{array}{l}\text { Grid blocks } \\
(\mathrm{i} \times \mathrm{j} \times \mathrm{k})\end{array}$ & $20 \times 1 \times 10$ & $20 \times 1 \times 10$ & $20 \times \times 20$ \\
\hline
\end{tabular}

The shortcomings of these simulations must be kept in mind. Some plausible production strategies were not studied. The entire height of the reservoir was perforated. Additional sensitivities to reservoir griding and some foam parameters should be explored. Despite these limitations. the results are believed to be valid and useful for comparing the relative performance of the various recovery processes.

\section{PROCESSES AND CONDITIONS}

Two production strategies in use or being considered for several reservoirs of this type were taken as base cases:
a) downdip WAG injection,
b) updip gravity-stabilised gas injection.

The degree of interlayer communication varies in many reservoirs of interest and was therefore chosen as a variable in the reservoir description in the model, with values of 0.001 .0 .01 , and 1 for the vertical transmissibility parameter $T_{\mathrm{v}}$.

Foam application was evaluated in three process types:

i) Mobility control by continuous injection of foam for a period. ii) Diversion of injectant through adding surfactant to one or more half-cycles of water at some point after gas breakthrough, and continuing WAG.

iii) Production-well treatment to control gas/oil ratio (GOR).

Foam processes (i) and (ii) were evaluated for production strategy (a) and process (iii) for production strategy (b). The diverting-foam process (ii) has been termed SAGA Injection (an acronym for Surfactant$A$ lternating- $G$ as $A$ meliorated injection) and was introduced in a recent paper 4 .

Production from the generic reservoir was simulated at an oil rate of $1000 \mathrm{Sm}^{3} / \mathrm{d}$ and an approximate voidage displacement until GOR exceeded a $1000 \mathrm{Sm}^{3} / \mathrm{Sm}^{3}$ cut-off value.

The foam modelling capabilities of the $\mathrm{K}$-value reservoir simulator STARS ${ }^{\mathrm{TM}}$ from Computer Modelling Group were used in this study 10,11,12. The simulator incorporates two foam models (empirical and population-balance). The empirical foam model assumes a local balance between foam generation and decay processes and accounts for effects of foam on gas relative permeability through a dimensionless interpolation parameter (see Appendix). This approach has been successfully applied to field pilots with hydrocarbon-gas foam ${ }^{10}$ and steam foam ${ }^{11,12}$. Those foam and process parameters considered most critical based on a review of field experience ${ }^{8}$ and prior work $^{13}$ were varied in the simulations: application mode, Mobility Reduction Factor (MRF), adsorption, surfactant volume and critical surfactant concentration. Table 2 summarises simulation variables and main results.

The main known critical foam parameters that were not considered in this study were the dependence of the gas mobility reduction on gas velocities, formation (layer) permeabilities, and foam persistence. STARS allows modeling the frequently observed shear-thinning effects of foam in porous media through a critical capillary number term, with $\mathrm{Nc}$ as a function of gas velocity. However. this dependence was not used in the present study. It is also well documented experimentally $9,14,15,16$ that gas mobility reduction by foam depends on the original permeability of the porous medium. Generally, the relative degree of gas mobility reduction is greater at higher permeabilities (within a range encompassing most non-fractured rocks). This is a most attractive feature of foam in that it serves to homogenize permeability contrasts.

The persistence, or longevity, of the mobility-reducing effect of foam is a critical parameter in production-well treatments and in some injectant diversion treatments. The loss of gas mobility reduction at extended times could be modelled as an approach to critical capillary pressure $^{17}$. Foam persistence could be increased by 
"fixating" the liquid phase constituting the lamellae by adding a polymer and possibly also a crosslinking agent. The resulting "fortified foam" (also known as polymer-enhanced foam and gel foam) might also provide a greater initial gas mobility reduction. Work is on-going to add gel foam functionality to STARS. However, some recent results ${ }^{18}$ suggest that formulating a fortified foam system carries added complexity and that, for example, a too high solution viscosity may lead to reduced foam efficiency in some circumstances. It also remains unproven whether polymer- and gel-foams are superior to well-formulated strong foams containing only surfactant.

\section{SIMULATION RESULTS}

\section{BASE CASES}

\section{Downdip WAG injection}

Communication between layers in the reservoir has a significant effect on the efficiency of WAG injection. Restricting vertical communication gives only a small delay in gas segregation and does not improve significantly the gas sweep efficiency in the defined model. However, restricted communication prevents water from slumping under gravity forces from the upper high-permeable layer into the bottom lowpermeable layer. The sweep of the lower layer remains poor in the cases with an interlayer permeability barrier (oil recovery of $36.1 \%$ of Stock Tank Oil In Place (STOIP) for $\mathrm{T}_{\mathrm{v}}=0.001$ and $39.1 \%$ of STOIP for $T_{V}=0.01$ ). Therefore, WAG injection appears to be more efficient in the case with no restriction to the crossflow ( $52 \%$ of STOIP for $T_{V}=1.0$ ), mainly due to the better sweep of water. A WAG process in a reservoir with restricted communication between layers having a poor sweep thus becomes an attractive candidate for improvement by SAG injection. The effects of restricted and unrestricted vertical communication is shown clearly by the GOR and production data in Figure 2 and the water saturation plots in Figure 3. The comparison of oil recoveries for two cases with different degree of communication between layers $\left(\mathrm{T}_{\mathrm{V}}=0.01\right.$ and $\left.\mathrm{T}_{\mathrm{V}}=1.0\right)$ is shown in Figure 4.

\section{Updip gas injection}

Gas injection in the reservoir was also slightly more efficient in the more isotropic reservoir (oil recovery of $38.1 \%$ of STOIP for $\mathrm{T}_{\mathrm{V}}=1.0$ and $37.1 \%$ of STOIP for $T_{V}=0.01$ ). In the restricted communication case, the downdip front movement and gas coning in the top high permeable layer happens faster than in the unrestricted-communication case, leading to an earlier gas breakthrough in the production well. Sweep of the low permeable lower layer is better when there is no cross flow restriction for the descending gas front (Figure 5).
In general, downdip WAG injection in this two-layer reservoir model was found to be more efficient than updip gas injection, especially when there was no restriction to the interlayer communication (Table 2).

\section{FOAM PROCESSES}

\section{General}

The required degree of gas mobility reduction by foam in order to achieve a significant sweep efficiency improvement over WAG injection in stratified reservoir will depend on the permeability contrast in the reservoir. In the layered reservoirs with low permeability contrast low gas mobility reduction by foam may be sufficient enough to improve conformance of the WAG flood. In this case a mobility control type foam process should be recommended. Stratified reservoirs with stronger permeability contrast may require stronger foam to block gas breakthrough in the high permeable thief zones. Position of the high and low permeable layers in the reservoir section, structural dip and gas segregation should be considered as well in selecting a foam process.

\section{Mobility control foam}

Foam used for in-depth mobility control was simulated at full and restricted inter-layer communication. The basic downdip WAG injection process was modified by an extended period of foam injection after gas breakthrough. Foam was injected by co-injecting surfactant and gas. Injected foam quality was between 60 and $80 \%$ (gas injection rate varied to stay below the specified maximum bottomwhole injection pressure of 380 bar).

At a foam MRF of 100 , recovery was significantly better than in the WAG base case. The data are listed in Table 2. Response was poorer in the restrictedcommunication case than at full communication because the injected foam had a tendency to plug the lower layer.

\section{Diverting foam}

For the WAG process and reservoir class considered, adding a foaming surfactant to (part of) a water halfcycle, without changing the operating procedure or the WAG parameters, is a simple and attractive foam process implementation ${ }^{4,13}$. Foam is generated in situ during the following gas half-cycles and, if effective, diverts gas and to some extent water towards unswept zones. Whether such a treatment will produce a "nearwellbore" or "deep" diversion depends on the volume injected and injectivity restrictions. The surfactant solution will follow water into water-invaded regions with no injectivity loss. In regions invaded by gas prior to treatment, surfactant solution that enters will generate mostly leave-behind lamellae which create a foam of modest mobility reduction ${ }^{14}$. In later gas cycles, gas will displace surfactant solution, generating foam by snap-off and/or lamella division mechanisms 15,19 . The strong foam thus created exists 
at some distance away from the near-wellbore zone which in many field trials appears to have been responsible for most of the injectivity loss. Thus, the effective penetration depth in this process may exceed that of foam injection.

The MRF for surfactant/gas displacement was set to a low value to account for these mechanistic differences. The runs were conducted by restarting from the corresponding WAG base case and injecting surfactant at or close to the original time of cut-off. After surfactant injection the reservoir was put back on WAG until the GOR again reached the maximum.

The simulations indicate that diversion by foam is effective in the generic reservoir, with or without restricted crossflow (Figure 4). All simulations show higher recovery than WAG and also better than for foam injection (Table 2), due to the smaller tendency to plug the lower-permeable layer when surfactant is injected as a separate slug. Recovery at cut-off as high as $58 \%$ of oil in place might be achieved for both communication options. The recovery improvement is better in the cases with restricted communication and represents an increase by as much as $40-50 \%$ of WAG recovery at GOR cut-off. Figure 6 shows the effect of the foam generated by slug injection on oil saturation distributions, Figure 7 shows recovery and the effect of diversion on GOR, important for many reservoirs operated at strict gas handling constraints. Figure 8 illustrates the different surfactant propagation pattern in the restricted and communicating reservoirs. The deep penetration of surfactant is favoured by a reversible surfactant adsorption in the simulation model.

\section{Production well treatment}

In an oil-production well suffering a high GOR, the desired effect of foam is to protect the producing zones from gas influx. The requirements for a GOR control foam are much as those for injectant blockage and diversion, with the addition of tolerance to flowing oil saturations for extended periods.

In the case of gravity stable gas injection the downdip producer suffers gas coning betore it is hit by the advancing global gas-oil contact ${ }^{20}$. Simulation on the generic reservoir model showed that foam treatment was more effective in the case with restricted communication between layers, but it did improve performance in both cases (Figure 5). Foam treatment comprising 5 days of injecting surfactant or foam, can delay the rise in GOR.

Treating the producer does not give as large a recovery improvement in absolute terms as the injector treatments, but the chemical volumes used are an order of magnitude smaller so these treatments have by far the greatest efficiency in terms of chemical utilisation. Figure 9 shows gas saturation plots for the restricted crossflow case. The different gas saturation pattern, caused by foam blocking off parts of the perforations, is noticeable.

\section{CRITICAL FOAM PARAMETERS}

\section{Mobility reduction factor}

Figure 10 shows that diversion treatments are sensitive to foam MRF. The sensitivity is greater at restricted communication. High gas mobility reduction by foam (MRF of 300) produces highly effective treatments, but even a moderate mobility reduction (MRF $=10$ ) can significantly improve oil recovery. A small slug treatment with highly effective foam ( 10 days injection of surfactant solution generating foam of $300 \mathrm{MRF}$ ) can give an equally large oil recovery improvement in the range of $7 \%$ of STOIP as a much larger slug with lower MRF (30 days surfactant injection generating foam of $M R F=100$ ) in the restricted communication case, where WAG efficiency is poor (Table 2). The process sensitivity is greater in the reservoir with restricted interlayer communication.

\section{Surfactant volume}

The effects of varying surfactant volume were studied in three ways: (1) by increasing, the surfactant concentration and MRF; (2) by shortening the surfactant injection period to the last 30 days of a 90 day water half-cycle, maintaining the same concentration and MRF; and finally (3) by injecting a high-concentration slug for only 10 days capable of making a very strong foam with an MRF of 300 . The first comparison, at vertical communication, increased oil recovery only from 56.1 to $57.1 \%$ of STOIP, showing that the influence of surfactant adsorption and increased surfactant concentration (from 0.7 to $2.1 \mathrm{wt}$ \%) are small at the "standard" values of these parameters. If the increased surfactant concentration allows to generate a stronger foam (MRF increased from 100 up to 300 ), it would give a significant recovery effect: $2 \%$ of STOIP increment in the full communication case and more than $19 \%$ of STOIP in the restricted communication case. Recovery factors for the two other comparisons (at restricted communication) are summarised in Figure 11.

\section{Surfactant adsorption}

The foam process is very sensitive to the surfactant adsorption. One run at restricted crossflow was done with the value of surfactant adsorption increased by a factor of 10 over that in the other cases. As seen from Table 4 (run sgla), this reduced the recovery significantly ( $5 \%$ of oil in place), though it was still better than in the WAG case.

\section{Critical surfactant concentration}

Two runs were performed with the critical surfactant concentration $w_{s}$ max: (a) reduced by a factor of 10 , and (b) increased by a factor of 10 from its "standard" value. The effect of critical surfactant concentration has significant influence on foam process efficiency (see Appendix). The increased threshold value for the strong foam generation in SAG injection reduced oil recovery 
in the restricted interlayer communication case by almost 3\% of STOIP (sg1_sc run in Table 2). When, in order to model an effectively deeper penetration of foam in the production well treatment with no restriction to cross flow between layers, by allowing foam strong mobility reduction to be formed at lower concentration, the oil recovery was increased by one extra percent of STOIP.

\section{PROCESS ECONOMICS}

The simulation results can be used to obtain relative estimates of process economics. Three simple evaluation criteria; surfactant volumetric efficiency $E_{S}$, cost efficiency $E_{c}$ and payback time $t_{p b}$ are defined:

$$
\begin{array}{lll}
\mathrm{E}_{\mathrm{s}} & =\frac{\mathrm{V}_{\mathrm{oe}}}{\mathrm{v}_{\mathrm{s}}} & (\mathrm{vol} / \mathrm{vol}) \\
\mathrm{E}_{\mathrm{c}} & =\frac{\mathrm{V}_{\mathrm{s}} \mathrm{C}_{\mathrm{s}}}{\mathrm{V}_{\mathrm{s}}} & (\$ / \mathrm{bbl}) \\
\mathrm{t}_{\mathrm{pb}}=\frac{\mathrm{v}_{\mathrm{s}} \mathrm{C}_{\mathrm{s}}}{\mathrm{Q}_{\mathrm{oe}} \mathrm{W}_{\mathrm{oe}}} & \text { (days) }
\end{array}
$$

$V_{S}$ is the surfactant volume injected and $C_{S}$ its unit cost. $V_{o e}$ is the volume of extra oil due to foam at an average daily rate of $Q_{0 e}$, and $W_{O}$ is the worth of oil. For simplicity, surfactant prices may be given "as injected" to include all costs. The values for these parameters in Table 4 were calculated at the current oil price $(\$ 15 / \mathrm{bbl})$ and roughly estimated surfactant cost $(\$ 5 / \mathrm{kg})$. It is seen that many of the foam processes are economically attractive. Cost efficiency is best for producer treatments at $\$ 1 / \mathrm{bbl}$ or less, with diversion treatments in the reservoir with permeability barriers of order $\$ 1-5 / \mathrm{bbl}$. Payback times are comparable to those of more established well treatment processes. For comparison, surfactant volumetric efficiencies for typical steam-foam field trials were between 49 and 1400 and the cost range for these is also similar ${ }^{8}$.

Designing foam for a reservoir with layers of high and low permeability being in good communication is more challenging and calls for careful optimization of the process parameters.

\section{CONCLUSIONS}

1. The present simulation study showed that in stratified dipping reservoir with unfavourable layering (low permeable zone underlying high permeable zone) down dip WAG injection tends to be still more efficient than continuous gravity stable gas injection.

2. Foam has significant potential as effective diverting treatment for WAG injection in sandstone heterogeneous reservoirs. Improvement offered by foam is greatest in stratified reservoirs with poor interlayer communication when WAG injection is least successful.

3. Foam treatments of production well against coning and cusping are also of high interest, offering slightly less potential than injector treatment at much lower cost due to smaller volume of chemicals. Cost per barrel of extra oil foam appears, by first approximation, to be typically on the order of $\$ 5 / \mathrm{bbl}$, but with favourable cases, such as production-well treatments, as low as $\$ 1 / \mathrm{bbl}$ or less.

4. The recovery improvement offered by foam is highly process and reservoir dependant, e.g. interlayer and vertical communication and the degree of foam mobility reduction are very sensitive parameters for foam application.

5. Because many critical parameters are uncertain in field application, more information is needed on foam behaviour at reservoir scale. Based on the present analysis, one or more foam field trials would prove invaluable.

\section{ACKNOWLEDGEMENTS}

This work is a part of the RUTH program for R\&D in improved oil recovery. The Foam sub-program is jointly executed by IKU and RF and supported by Shell, Statoil, Norsk Hydro, Saga Petroleum, Conoco, Mobil in addition to the Research Council of Norway.

\section{REFERENCES}

1. Hinderaker, L., Bygdevoll, J., Bu, T., Nybråten, G., Krakstad, O.S.: "IOR Reservoir Potential of Norwegian North Sea Sandstone Reservoirs", 6-th European IOR-Symposium, Stavanger, May 21-23, 1991, 957-966.

2. Surguchev, L.M., Hanssen, J.E., Johannessen, H.M. and Abusdal, T.: "Improved Recovery Strategies for Heterogeneous Reservoir", SPE 28718, SPE International Petroleum Conference and Exhibition of Mexico, Veracruz, 10-13 October 1994.

3. Surguchev, L.M., Korbøl, R., and Krakstad, O.S.: "Optimum Water Alternate Gas Injection Schemes for Stratified Reservoirs", SPE 24646, 1992 SPE Annual Technical Conference and Exhibition, Washington, October 4-7, 1992, EOR, pp 167-175.

4. Hanssen, J.E., Surguchev, L.M.. Svorstøl, I., Blaker, T.: "SAGA Injection: A New Combination IOR Process for Stratified Reservoirs", 7th European IOR Symposium, Moscow, Russia, October 27 29, 1993. 
6. Nystad, A.N., Njå, S., Hinderaker, L., Bygdevoll, J., Johannessen, H.M.: "Improved Oil Recovery. The Norwegian Case", 14th World Petroleum Congress, Stavanger, 29 May - 1 June 1994.

7. Solheim A., Surguchev, L.M.: "Foam Simulation Using STARS", RUTH Seminar 1994, 5-6 September 1994, p18.

8 . Hanssen, J.E., Holt, T., Surguchev, L.M.: "Foam Processes: An assessment of their potential in North Sea reservoirs based on a critical evaluation of current field experience." SPE 27768, SPEIDOE 9th Symposium on Improved Oil Recovery, Tulsa, April, 17-20, 1994.

9. SPOR Monograph, Chapter Sweep Improvements, Hanssen, J.E.: "Foam for Gas Flooding", Stavanger, 1992.

10. Mohammadi, S.S., Coombe, D.A.: "Field Application and Simulation of Foam for Gas Diversion", 8th European Symposium on Improved Oil Recovery, Vienna, Austria, 15-17 May 1995.

1.1. Mohammadi, S.S., Coombe, D.A. and Stevenson, V.M.: "Test of Steam Foam Process for Mobility Control in South Casper Creek Reservoir," J.Can.Pet. Tech., v 23 \#10, p49, December 1993.

12. Lau, E.C., Coombe, D.A.: "History Matching the Steam/Foam Injection Process in a Thick Athabasca Tar Sand Reservoir", J.Can.Pet.Tech., v 33\#1, p56, January 1994.

13. Surguchev, L.M., Hanssen, J.E., Svorstøl, I.: "SAG Injection in the North Sea Stratified Reservoir: Flow Experiment and Simulation", SPE 28847, European Petroleum Conference, London, 25-27 October 1994.

14. Falls, A.H., et al.: "Development of a mechanistic foam simulator: The population balance and generation by snap-off," SPERE (August 1988) 884-

15. Hirasaki, G.J.: "The Steam-Foam Process," JPT (May 1989) 449-456; Supplement to SPE 19505.

16. Falls, A.H. et al.: "The Apparant Viscosity of Foams in Homogeneous Bead Packs", SPERE (May 1989).

17. M. Dalland. J. E. Hanssen: Gas-blocking foams. Chapter $\mathbf{8}$ in "Foams: "Fundamentals and applications in the petroleum industry", L.Schramm, ed. Amer. Chem. Soc. 1994.

18. J. E. Hanssen. A. Stavland: "A study of fortified foams for improvedgas- blocking efficiency at reservoir conditions", paper in preparation (to be published in 1995)

19. Radke, C.J. and Ransohoff, T.C.: "Mechanisms of Foam Generation in Glass-Bead Packs", SPERE (May 1988) 573-585.

20. Surguchev, Søgnesand, S., Skauge, A., Aarra, M.A.: "Modelling and History Matching of Foam Field Pilot, Oseberg Field", $8 \mathrm{th}$ European Symposium on Improved Oil Recovery, Vienna, Austria, 15-17 May 1995.

21. Chou, S.I.: "Percolation Theory of Foam in Porous Media", SPE/DOE 20239, 7th Symposium of EOR. Tulsa, OK, April 22-25, 1990.

\section{APPENDIX}

\section{Empirical foam model}

STARS simulator is a fully-featured, both field and laboratory scale reservoir simulator. The empirical foam formulation in STARS utilises the basic assumption that foam creation and coalescence mechanisms occur in the reservoir whenever gas and surfactant coexists ${ }^{10}$. Correct description of surfactant component flow and adsorption (adsorption isotherms) are important requirements for the foam model. Foam effects on gas mobility and flow pathways are modelled via modified relative permeability curves. The model allows to account for foam sensitivity to the different factors through a dimensionless interpolation parameter. The gas permeability used in each particular computation is obtained by interpolating between gas and foam permeability curves using the following expression 11,12:

$$
\begin{aligned}
& F M=[1+M R F \cdot S C \cdot O T \cdot C N \cdot C N G \cdot L C]^{-1} \\
& M R F=\frac{\Delta p_{\text {foam }}}{\Delta p_{\text {nofoam }}}
\end{aligned}
$$

where:

$$
S C=\left(\frac{w_{s}}{w_{s}^{\max }}\right)^{e_{s}}
$$

$w_{S}=$ Surfactant concentration in mole fraction.

$w_{s} \max =$ The maximum surfactant concentration where it is relevant.

$\mathrm{e}_{\mathrm{S}} \quad=$ Parameter for the influence of surfactant concentration.

$$
\begin{aligned}
& O T=\left(\frac{S_{o}^{\max }-S_{o}}{\left.S_{o}^{\max }\right)^{e_{o}}}\right. \\
& S_{o}=\text { Oil saturation. }
\end{aligned}
$$


$S_{O}{ }^{\max }=$ The maximum oil saturation above which no foam can exist.

$e_{o} \quad=$ Parameter for the influence of oil saturation.

$C N=\left(\frac{N_{c}^{r e f}}{N_{c}}\right)^{e_{v}}$

$N_{c} \quad=$ Capillary number .

$N_{C}^{r e f}=$ Capillary number at reference foam.

$e_{v} \quad=$ Parameter for the influence of capillary

number.

$C N G=\left(\frac{N_{c g}-N_{c}^{r e f}}{N_{c g}}\right)^{e_{v}}$

$N_{c g} \quad=$ Critical capillary number for foam

generation.

$e_{g} \quad=$ Parameter for the contribution of capillary

number on foam generation.

$x_{\text {nemx }}^{c r}=$ Critical mole fraction of the light component in the oil.

$x_{\text {numx }}=$ Mole fraction of the light component in the

oil.

$\mathrm{e}_{\mathrm{x}} \quad=$ Parameter for the influence of light oil component.

$L C=\left(\frac{x_{n u m x}^{c r}-x_{n u m x}}{x_{n u m x}^{c r}}\right)^{e_{x}}$

$\Delta p_{\text {foam }}=$ Inlet-outlet pressure difference in a reference core foam flood at reference condition.

$\Delta p_{\text {nofoam }}=$ Inlet-outlet pressure difference in a reference core flood with no foam.

Capillary number is determined according to the following formula:

$N_{c}=\frac{v_{g} \mu_{g}}{\gamma \phi}$

where:

$v_{g} \quad$ = gas velocity

$\mu_{g} \quad=$ gas viscosity

$\gamma \quad=$ interfacial tension

$\phi \quad=$ porosity

The term MRF specifies the reference foam mobility reduction factor which is usually determined directly from experiment. Theoretically, it can be viewed as a normalised lamella (or bubble) density times a normalised pressure drop per lamella, since

$\Delta p_{\text {foam }}=\frac{\varphi_{a} \gamma}{r_{p}} \quad$ and $\quad \Delta p_{g a s}=\frac{\varphi_{b} L \mu_{g} \nu_{g}}{r_{p}^{2}}$ where $\varphi_{a}$ and $\varphi_{b}$ are pore geometry factors. These then give
$M R F=\frac{\varphi_{c} n_{l} r_{p}}{N_{c}^{\text {ref }}}$

or equivalently

$M R F=\frac{\varphi_{d} n_{b}}{N_{c}^{r e f} n_{p}}$

which is a product of a pore geometry factor divided by a reference capillary number times either (a) number of lamella per unit length normalise by pore length or (b) number of bubbles per unit volume normalised by the number of pores per unit volume. Here $L$ for gas flow is $\frac{1}{n_{l}}$. The above is equivalent to work by Falls et $a l^{16}$, their equations (24) or (41a). The first two factor represent a normalised (with respect to gas flow) pressure drop per lamella; the last gives a normalised measure of the number of lamellas or bubbles. The remaining factors in the expression for FM describe the stability of the lamellae under various conditions, such as varying surfactant concentration, flow velocities, and the presence of oil; and are reminiscent of the $P_{S L}$ factor of $\mathrm{Chu}^{21}$, his equation (20).

As an example the Figure 1 shows the effect of surfactant concentration on the gas MRF in the foam containing region and its exponent $e_{S}$ in the interpolation factor formulation.

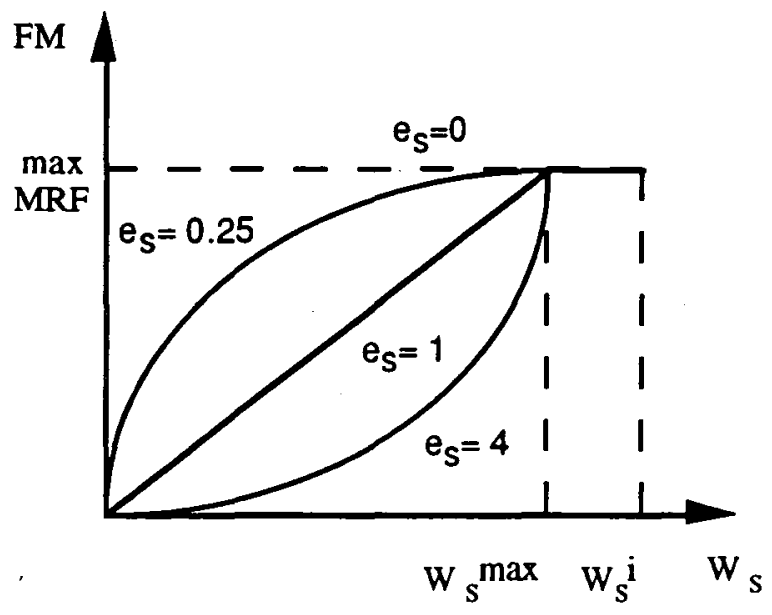

Figure 1. Effect of the surfactant concentration on the foam mobility (FM). 
Table 2: Simulation results and parameters for idialized North Sea reservoir.

\begin{tabular}{|c|c|c|c|c|c|c|c|c|c|c|c|c|c|c|}
\hline $\begin{array}{l}\text { Prod. strategy } \\
\text { Injection mode }\end{array}$ & $\mathbf{T}_{\mathbf{v}}$ & $\begin{array}{r}\text { Run } \\
\text { name }\end{array}$ & $\begin{array}{l}\text { Surf } \\
\text { wt \% }\end{array}$ & $\begin{array}{l}\text { Surf. } \\
\text { days }\end{array}$ & $\begin{array}{l}\text { Surf. } \\
\text { tons }\end{array}$ & $\begin{array}{l}\text { Foam } \\
\text { MRF. }\end{array}$ & $\begin{array}{l}\text { Ads. } \\
\mathrm{mg} / \mathrm{g}\end{array}$ & $\begin{array}{c}w_{s} \\
\text { wt } \%\end{array}$ & $\begin{array}{l}\text { Days to } \\
\text { cut-off }\end{array}$ & $\begin{array}{l}\text { Oil recv. } \\
10^{3} \mathrm{Sm}^{3}\end{array}$ & $\begin{array}{c}\text { Recv. } \\
\%\end{array}$ & $\begin{array}{c}E_{S} \\
m^{3} / m^{3}\end{array}$ & $\begin{array}{c}\mathbf{E}_{\mathbf{c}} \\
\$ / \mathbf{b} \mathbf{b l}\end{array}$ & $\begin{array}{c}\mathbf{t}_{\mathrm{pb}} \\
\text { days }\end{array}$ \\
\hline $\begin{array}{l}\text { WAG } \\
\text { wag, foam, wag } \\
\text { wag, surf, wag }\end{array}$ & $\begin{array}{l}1 \\
1 \\
1 \\
1 \\
1 \\
1 \\
1 \\
1\end{array}$ & $\begin{array}{r}w g \\
f l t \\
s g \\
s g \_10 d \\
s g-m \\
s g m 100 \\
s g m 300 \\
\text { mcf }\end{array}$ & $\begin{array}{r}0 \\
0.7 \\
0.7 \\
2.1 \\
0.7 \\
0.7 \\
2.1 \\
0.07\end{array}$ & $\begin{array}{r}\overline{0} \\
90 \\
90 \\
10 \\
90 \\
90 \\
90 \\
111\end{array}$ & $\begin{array}{r}0 \\
771 \\
771 \\
253 \\
771 \\
771 \\
2281 \\
96\end{array}$ & $\begin{array}{r}1 \\
100 \\
100 \\
300 \\
10 \\
300 \\
300 \\
5\end{array}$ & $\begin{array}{l}-\overline{-} \\
0.05 \\
0.05 \\
0.05 \\
0.05 \\
0.05 \\
0.05 \\
0.05\end{array}$ & $\begin{array}{l}-\overline{-} \\
0.12 \\
0.12 \\
0.12 \\
0.12 \\
0.12 \\
0.12 \\
0.12\end{array}$ & $\begin{array}{l}1440 \\
1668 \\
1682 \\
1621 \\
1594 \\
1959 \\
2090 \\
1461\end{array}$ & $\begin{array}{r}1425 \\
1509 \\
1529 \\
1509 \\
1491 \\
1591 \\
>1620 \\
1436\end{array}$ & $\begin{array}{l}52.1 \\
55.1 \\
56.1 \\
55.2 \\
54.6 \\
58.1 \\
59.2 \\
53.1\end{array}$ & $\begin{array}{r}- \\
87 \\
108\end{array}$ & $\begin{array}{r}7.30 \\
5.89\end{array}$ & $\begin{array}{r}11 \overline{1} \\
95\end{array}$ \\
\hline $\begin{array}{l}\text { Gas drive } \\
\text { producer foam } \\
\text { treatement }\end{array}$ & $\begin{array}{l}1 \\
1 \\
1 \\
1\end{array}$ & $\begin{array}{r}\text { gas } \\
\text { S } \\
\text { ss } \\
\text { so }\end{array}$ & $\begin{array}{l}\overline{1} \\
0 . \overline{7} \\
2.1 \\
2.1\end{array}$ & $\begin{array}{l}- \\
5 \\
5 \\
5\end{array}$ & $\begin{array}{r}\overline{4} \\
126 \\
126\end{array}$ & $\begin{array}{r}1 \\
100 \\
100 \\
100\end{array}$ & $\begin{array}{l}-\overline{-} \\
0.05 \\
0.05 \\
0.05\end{array}$ & $\begin{array}{r}0 . \\
0.1 \overline{2} \\
0.12 \\
0.012\end{array}$ & $\begin{array}{l}1031 \\
1080 \\
1127 \\
1145\end{array}$ & $\begin{array}{l}1032 \\
1075 \\
1122 \\
1140\end{array}$ & $\begin{array}{l}38.1 \\
39.1 \\
41.1 \\
42.1\end{array}$ & $\begin{array}{r}-\overline{819} \\
571 \\
686\end{array}$ & $\begin{array}{l}- \\
0.78 \\
1.11 \\
0.93\end{array}$ & $\begin{array}{l}- \\
3 \\
7 \\
7\end{array}$ \\
\hline $\begin{array}{l}\text { WAG } \\
\text { wag, foam, wag } \\
\text { wag, surf, wag }\end{array}$ & $\begin{array}{r}0.01 \\
0.001 \\
0.01 \\
0.01 \\
0.01 \\
0.01 \\
0.01 \\
0.01 \\
0.01 \\
0.01 \\
0.01\end{array}$ & $\begin{array}{r}\text { wg1 } \\
\text { wg2 } \\
\text { fl1t } \\
\text { sg1 } \\
\text { sglv } \\
\text { sgl-m } \\
\text { sglm } \\
\text { sg1a } \\
\text { sg1_10d } \\
\text { sg1_sc } \\
\text { mcf1 }\end{array}$ & $\begin{array}{r}\mathbf{0} \\
\mathbf{0} \\
0.7 \\
0.7 \\
0.7 \\
0.7 \\
2.1 \\
0.7 \\
2.1 \\
0.7 \\
0.07\end{array}$ & $\begin{array}{r}- \\
- \\
90 \\
90 \\
30 \\
90 \\
90 \\
90 \\
10 \\
90 \\
180\end{array}$ & $\begin{array}{r}\mathbf{0} \\
\mathbf{0} \\
771 \\
771 \\
257 \\
771 \\
2281 \\
771 \\
253 \\
771 \\
155\end{array}$ & $\begin{array}{r}1 \\
1 \\
100 \\
100 \\
100 \\
10 \\
300 \\
100 \\
300 \\
100 \\
5\end{array}$ & $\begin{array}{r}- \\
-\overline{0} \\
0.05 \\
0.05 \\
0.05 \\
0.05 \\
0.05 \\
0.50 \\
0.05 \\
0.05 \\
0.05\end{array}$ & $\begin{array}{r}\overline{-} \\
0.12 \\
0.12 \\
0.12 \\
0.12 \\
0.12 \\
0.12 \\
0.12 \\
1.2 \\
0.12\end{array}$ & $\begin{array}{r}1065 \\
975 \\
1438 \\
1609 \\
1407 \\
1276 \\
2340 \\
1311 \\
1312 \\
1301 \\
1185\end{array}$ & $\begin{array}{r}1065 \\
947 \\
1259 \\
1333 \\
1250 \\
1172 \\
>1611 \\
1203 \\
1196 \\
1196 \\
1130\end{array}$ & $\begin{array}{l}39.1 \\
36.1 \\
46.1 \\
49.1 \\
46.1 \\
43.0 \\
59.1 \\
44.1 \\
43.9 \\
43.9 \\
41.1\end{array}$ & $\begin{array}{r}- \\
- \\
201 \\
278 \\
576 \\
111 \\
143\end{array}$ & $\begin{array}{r}- \\
3.16 \\
2.29 \\
1.10 \\
5.73 \\
4.44\end{array}$ & $\begin{array}{r}- \\
- \\
79 \\
83 \\
25 \\
81 \\
73\end{array}$ \\
\hline $\begin{array}{l}\text { Gas drive } \\
\text { producer foam } \\
\text { treatement }\end{array}$ & $\begin{array}{l}0.01 \\
0.01 \\
0.01\end{array}$ & $\begin{array}{r}\text { gas1 } \\
\text { s1 } \\
\text { sls }\end{array}$ & $\begin{array}{l}-\overline{7} \\
2.1\end{array}$ & $\begin{array}{l}\overline{5} \\
5\end{array}$ & $\begin{array}{r}- \\
42 \\
126\end{array}$ & $\begin{array}{r}1 \\
100 \\
100 \\
\end{array}$ & $\begin{array}{l}\overline{-} \\
0.05 \\
0.05\end{array}$ & $\begin{array}{l}0 . \overline{2} \\
0.12\end{array}$ & $\begin{array}{l}1013 \\
1190 \\
1233 \\
\end{array}$ & $\begin{array}{l}1013 \\
1184 \\
1227 \\
\end{array}$ & $\begin{array}{l}37.1 \\
43.1 \\
45.1 \\
\end{array}$ & $\begin{array}{r}- \\
3257 \\
1359 \\
\end{array}$ & $\begin{array}{l}-\overline{-} \\
0.20 \\
0.47\end{array}$ & $\begin{array}{l}- \\
2 \\
2\end{array}$ \\
\hline
\end{tabular}

${ }^{*}$ Calculated as $100 \%$ surfactant of density $1000 \mathrm{~kg} / \mathrm{m}^{3}$. Surf. = surfactant Ads. = adsorption; recv. = recovery. $\mathrm{T}_{\mathrm{v}}, \mathrm{w}_{\mathrm{S}}, \mathrm{E}_{\mathrm{S}}, \mathrm{E}_{\mathrm{c}}, \mathrm{l}_{\mathrm{pb}}:$ see text.

Oil originally in place: $2.3910^{3} \mathrm{~m}^{3}$ 
WAG Injection - Effect of Interlayer Communication

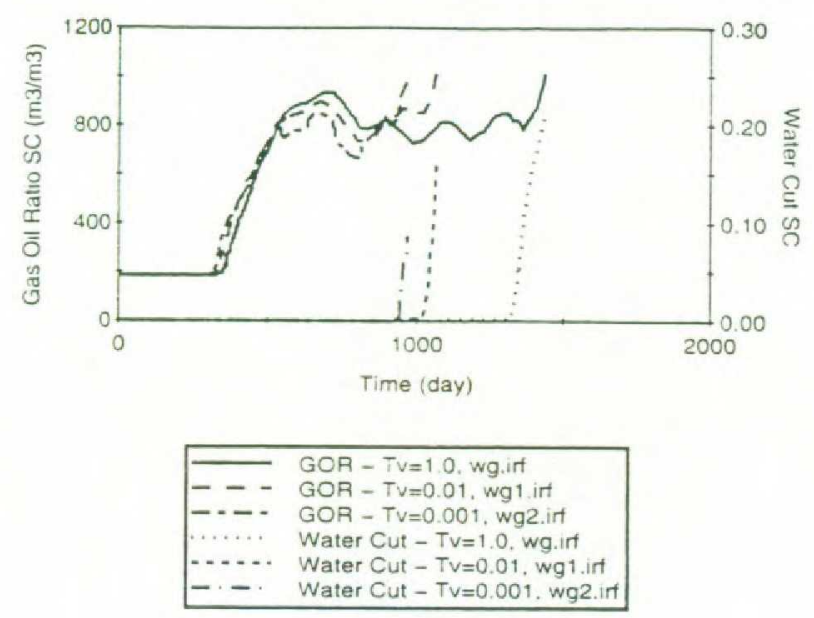

Figure 2: Simulated production GOR and water-cut during WAG injection in generic North Sea reservoir at varying vertical communication between layers. Run name and value transmissibility parameter indicated.

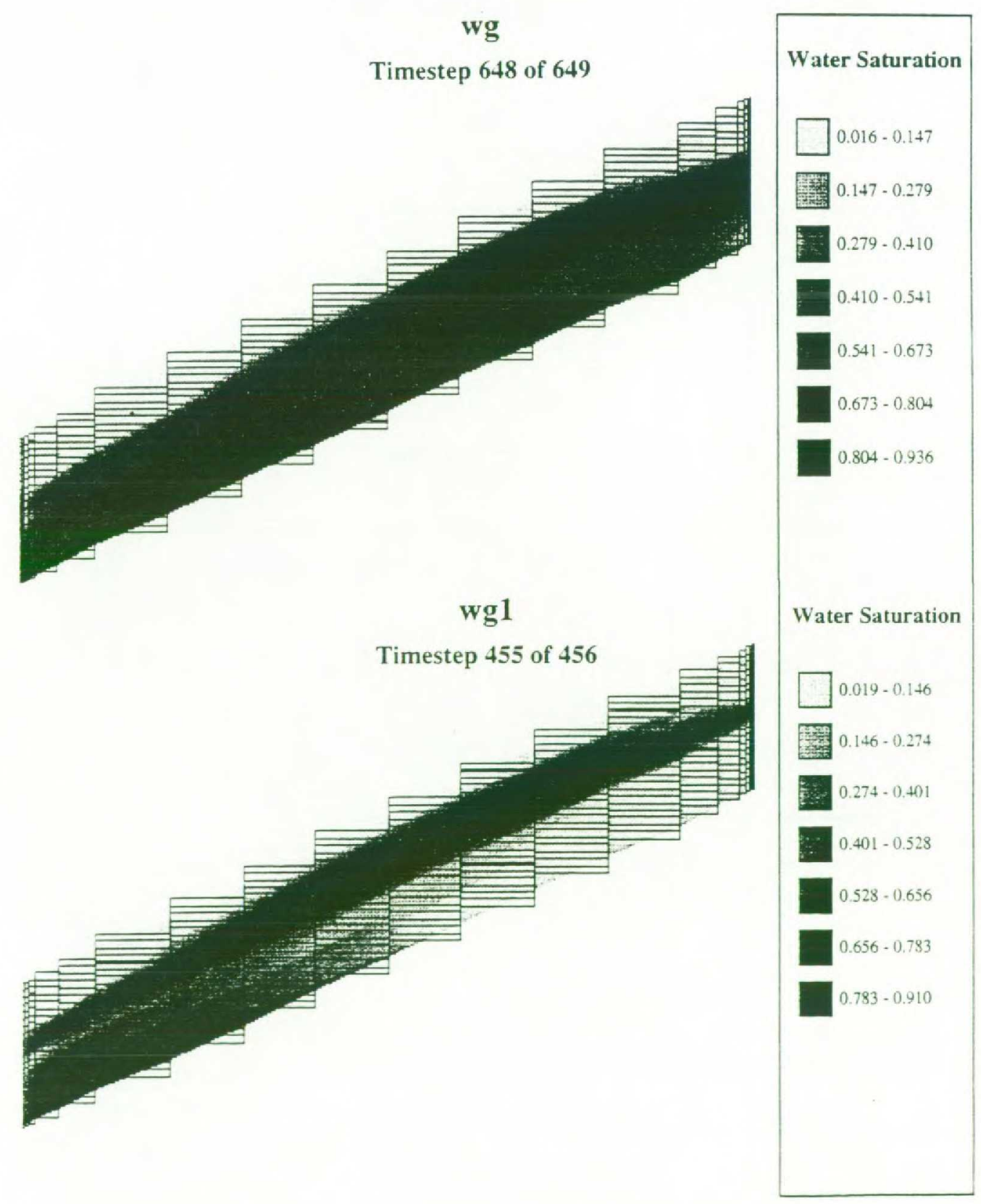

Figure 3: Simulated water saturation at the end of WAG injection in generic North Sea reservoir with and without permeability barrier between the upper and lower layers. 


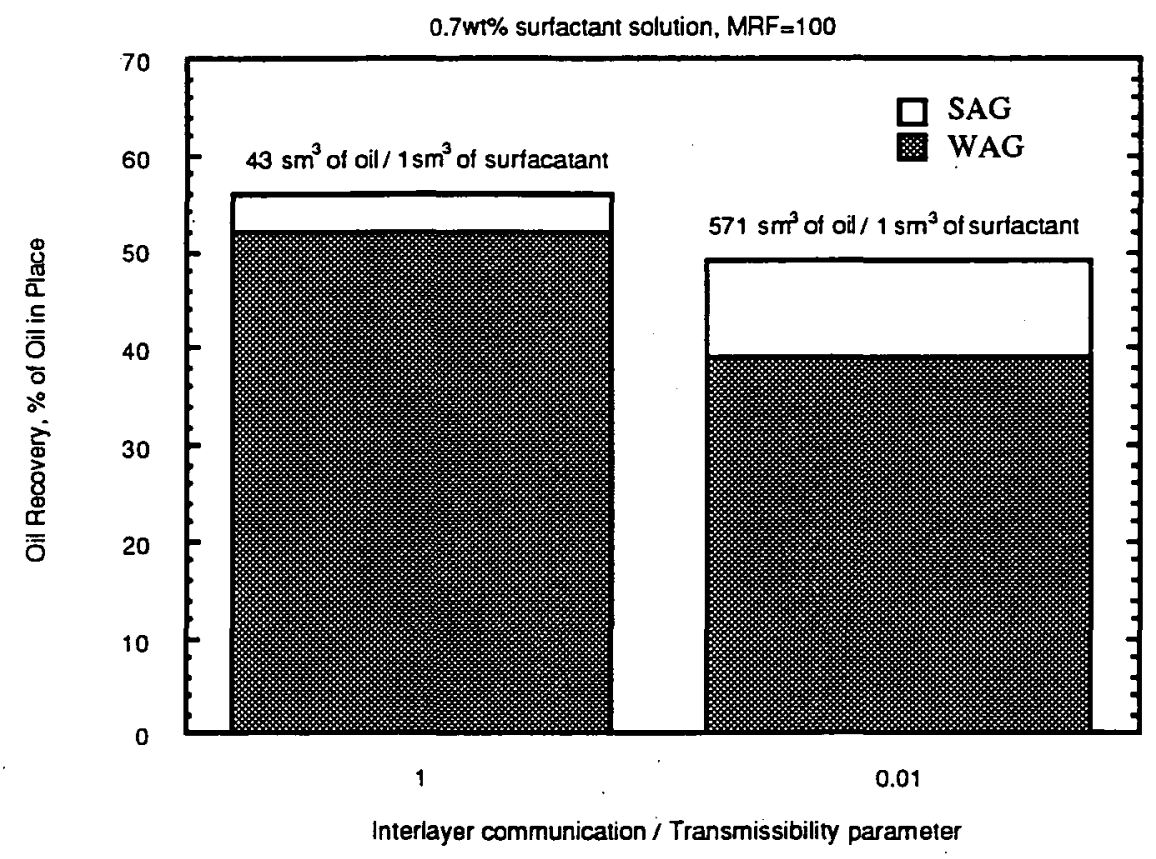

Figure 4: WAG improvement by foam in the reservoir with different degrees of interlayer communication.

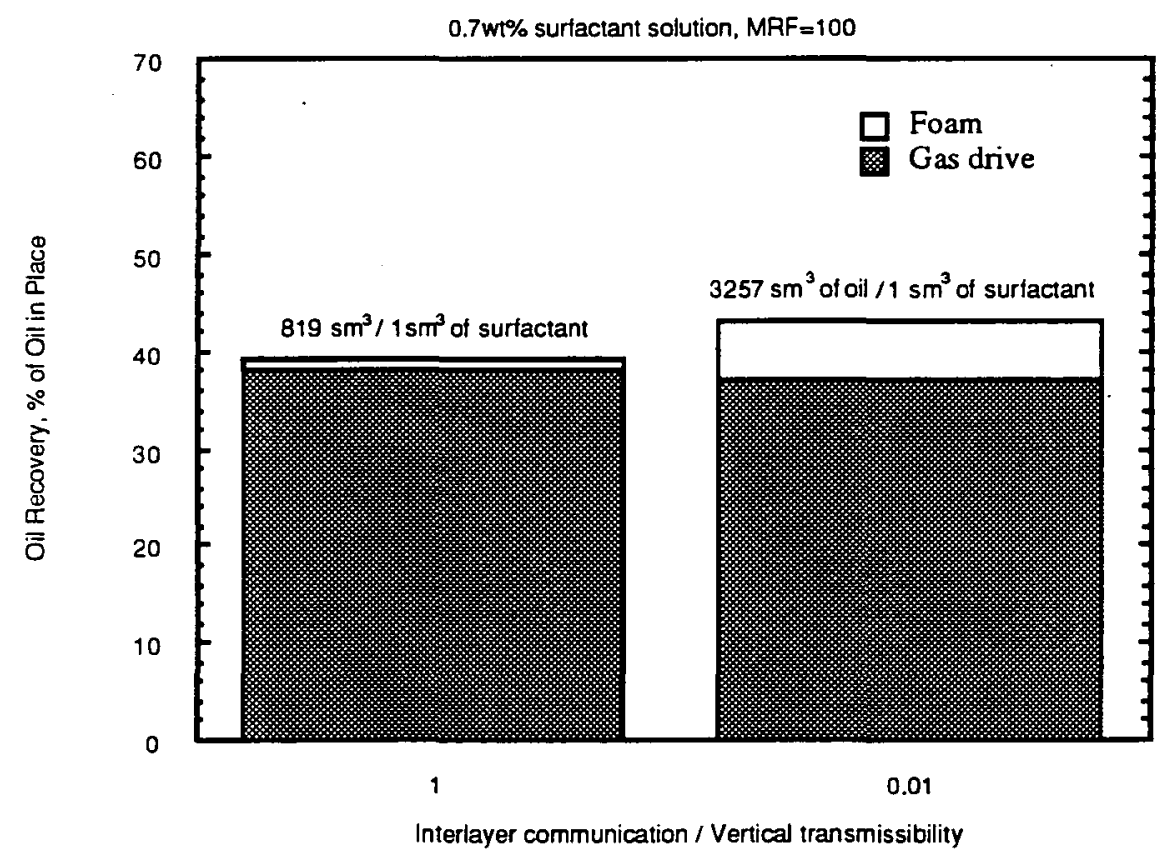

Figure 5: Production well treatment by foam in the reservoir with different degrees of interlayer communication. 
wg1

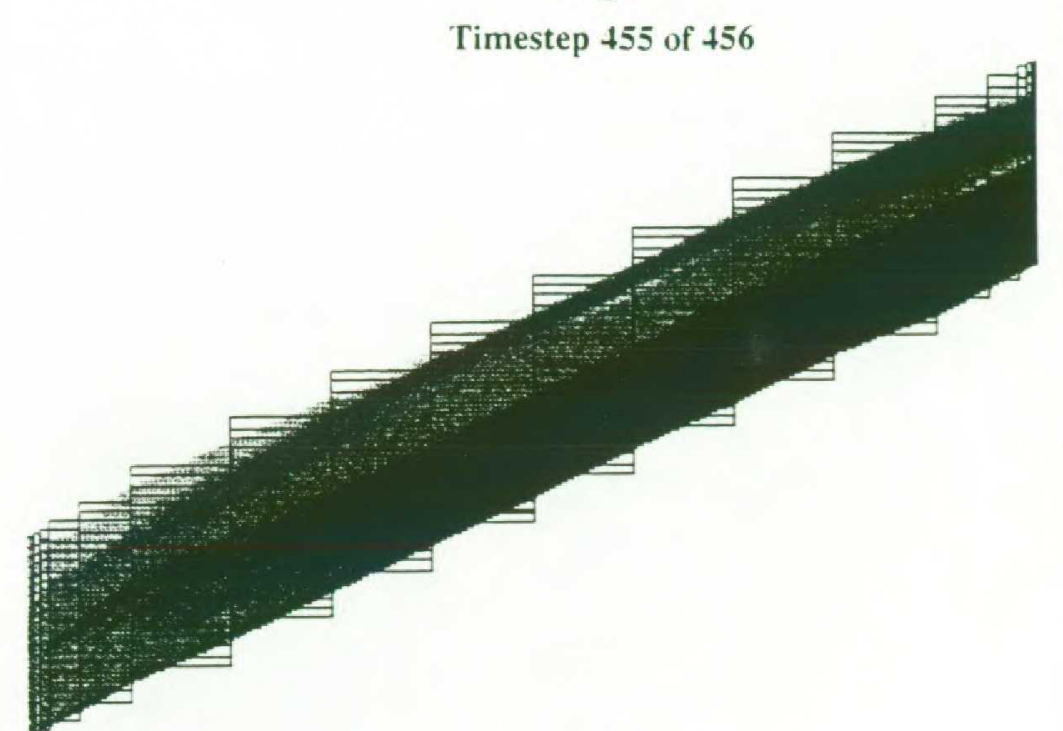

Oil Saturation

$\operatorname{sg} 1$

Timestep 715 of 716

Oil Saturation

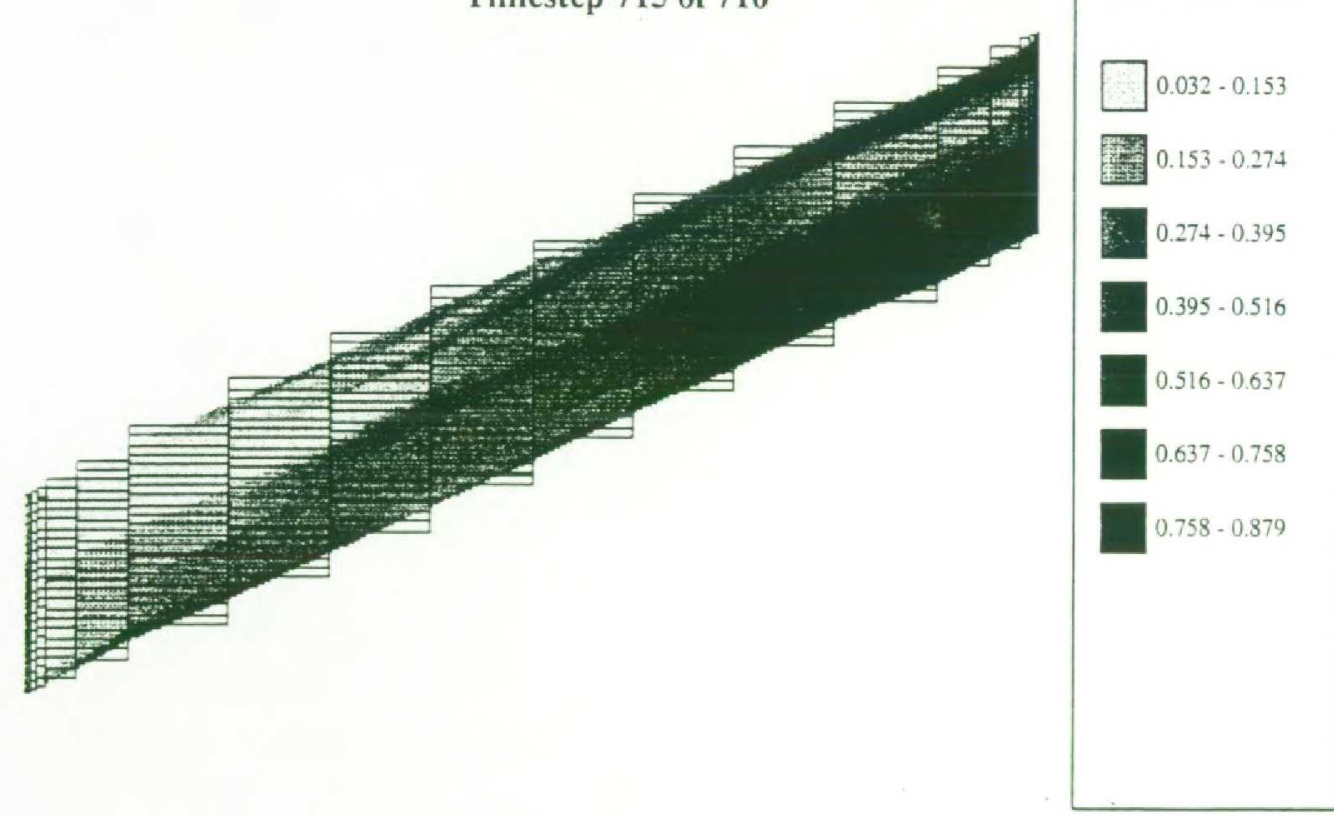

Figure 6: Simulated oil saturation in generic North Sea reservoir with permeability barrier between layers at end of WAG base case (top) and of WAG assisted by diverting foam

\section{(SAG).}

SAG vS WAG

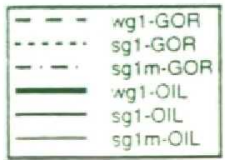

GAS-OIL AATIO $(\mathrm{m} 3 / \mathrm{m} 3)$

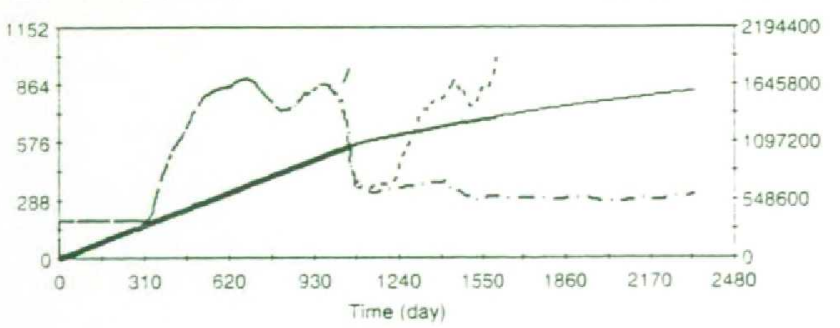

Figure 7: Simulated oil production and production GOR in generic North Sea reservoir with restricted interlayer communication for WAG base case and diverting foam, at a foam mobility reduction factor MRF of 100 (sgi) or 300 ( $\mathrm{sg} \mathrm{l} \mathrm{m}$ ). 


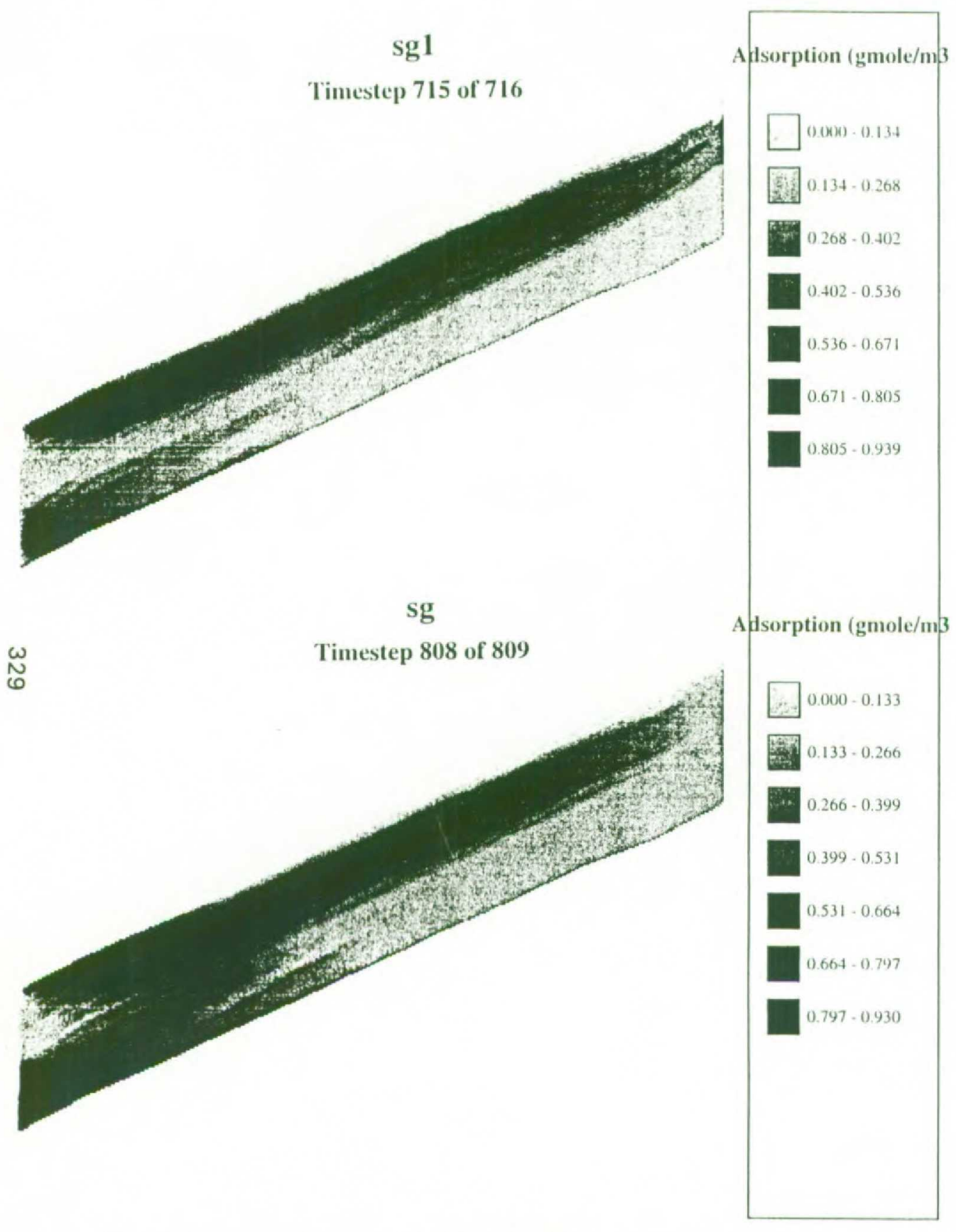

Figure 8: Simulated surfactant adsorption, reflecting surfactant transport, for diverting foam (SAG) in generic North Sea reservoir with restricted (top) and full (bottom) interlayer communication.

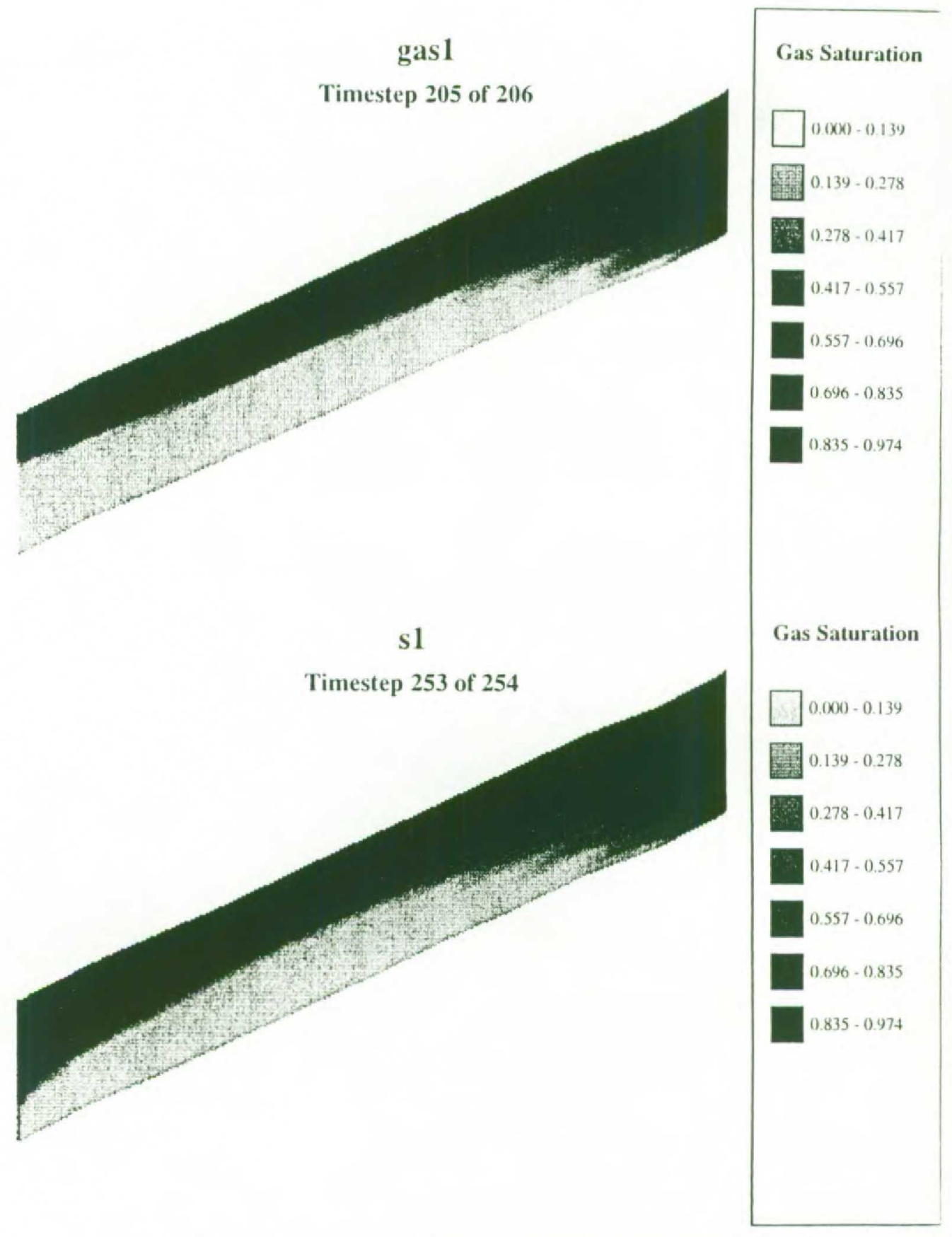

Figure 9: Simulated gas saturation in generic North Sea reservoir with permeability barrier when gas is injected into the upper well. Top: No protection against gas. Bottom Production well treated with foam. 


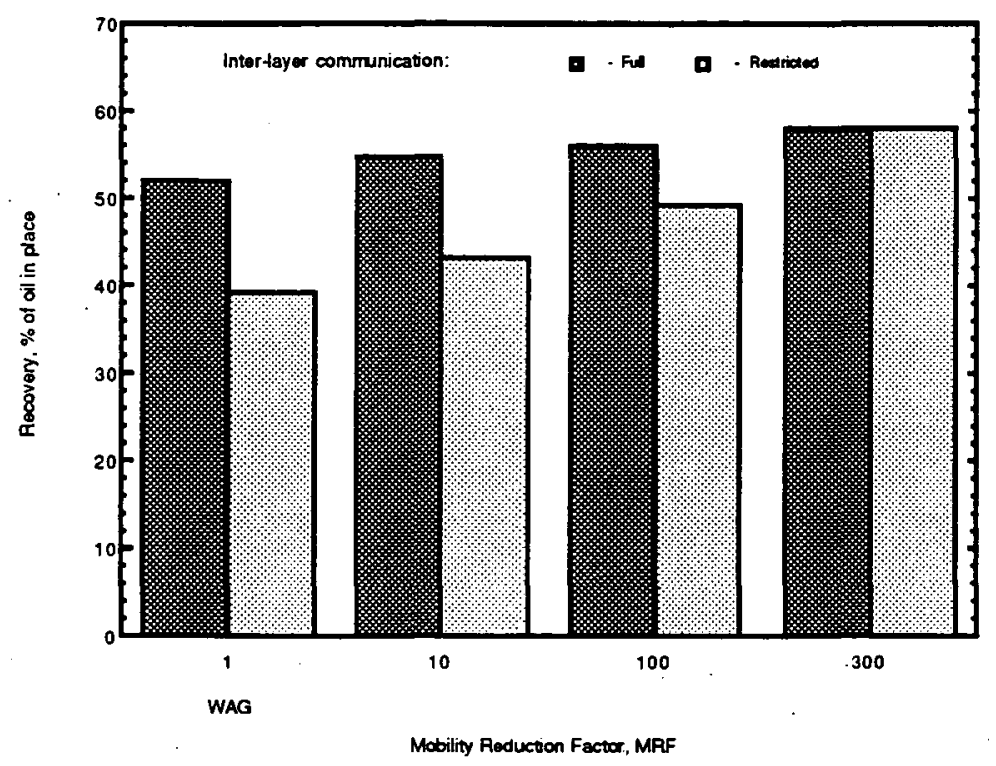

Figure 10: Simulated recovery for diversion treatments with full and restricted vertical communication at indicated values of foam MRF.

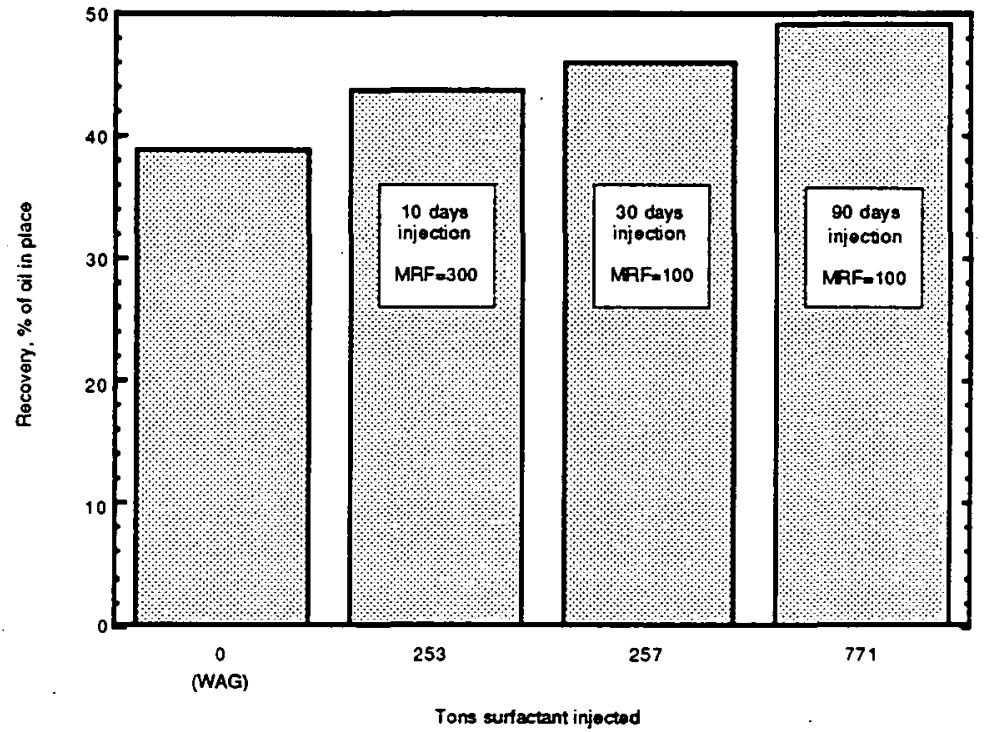

Figure 11: Recovery for foam diversion treatments with restricted vertical communication at individual foam volume injected. Generic North Sea reservoir simulation. 